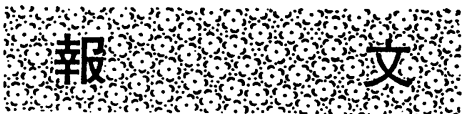

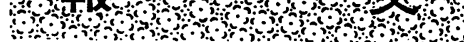

\title{
Studies on the Compounds Related to PCB (VI)
}

\section{Determination of Polychlorinated Quaterphenyl (PCQ) in Kanemi Rice Oil Caused the "Yusho" and Investigation on the PCQ Formation}

(Received January 20, 1978)

Hideaki Miyata, Yasuyuki Murakami and Takashi Kashimoto

(Osaka Prefectural Institute of Public Health: 3-69, Nakamichi 1-chome, Higashinari-ku, Osaka)

Our earlier study revealed that unknown organochlorinated compounds, which were mainly composed of polychlorinated quaterphenyl(PCQ), were present largely in Kanemi rice oil caused the "Yusho."

In this report, in order to determine PCQ in Kanemi rice oil, a simple analytical method for PCQ was established and PCQ standard was prepared.

The actual PCQ level in the oil was 490 to $866 \mathrm{ppm}$, equivalent to $0.88 \sim 3.46$ times more than the actual PCB level found in the oil.

Moreover, the chlorine concentration of PCQ in the oil was 207 to $450 \mathrm{ppm}$ by MCDGC. From this result, it was confirmed that PCQ occupied $72 \sim 89 \%$ of the unknown in the oil.

In addition to clarify the cause why large quantities of PCQ was present in the oil, Kanechlor 400 (KC-400), which had been used as the thermotransfer media, was analysed for PCQ. Consequently, it became clear that PCQ had generated at level of $690 \sim 31,000$ $\mathrm{ppm}$ in the thermotransfer media.

Therefore, it was investigated whether PCQ would be generated thermochemically from PCB.

KC-400, Japanese commercial PCB preparation containing 48\% chlorine, was poured in a glass ampoule. After the ampoule was sealed, it was heated under various conditions. Consequently, it was confirmed that PCQ was generated thermochemically from KC-400 by heating $\mathrm{KC}-400$ at high temperature in a glass ampoule. The PCQ level in KC-400 increased by heating $\mathrm{KC}-400$ at higher temperature and during longer period. Moreover, it was clear that the PCQ formation was more accelerated by heating under the presence of stainless steel and water, and consequently the PCQ concentration in heated KC-400 became the maximum level, 47,000 ppm.

\section{Introduction}

Previously, we reported that organochlorinated compounds, which were free from $\mathrm{PCB}$ and PCDF, were detected largely in Kanemi rice oil caused the "Yusho" and that the chlorine concentration of them was 287 to $537 \mathrm{ppm}$, equivalent to $1.1 \sim 4.1$ times more than the chlorine level of PCB in the oil, by neutron activation analysis. ${ }^{12}$,2) Moreover, GC-MS analysis revealed that the unknown was mainly composed of polychlorinated quaterphenyls (PCQs). ${ }^{1,2)}$

In this paper, in order to determine the actual PCQ concentration in Kanemi rice oil, it was attempted to prepare the PCQ standard for the PCQ determination and to establish a simple analytical method for PCQ in samples.

On the other hand, until the present there was only a report that PCQ was generated photochemically from original PCB by irradiating PCB 
with UV lamps and sunlight. ${ }^{3)}$ However, the result couldn't be applied to the PCQ formation in the Kanemi rice oil.

Therefore, the PCQ formation by heating PCB was investigated.

\section{Materials and Methods}

\section{1 Materials}

KC-400: It was distributed to our laboratory in 1972 by the Ministry of Health and Welfare.

Kanemi rice oils: The oils were manufactured on February 5th, 9th, and 10th in 1968, and their lot no. were 821119079, 15520, and 16793, respectively.

KC-400 used as the thermotransfer media: $\mathrm{H}-1$ was used for 1958 to 1972 at 180 to $270^{\circ} \mathrm{C}$ at a chemical factory. It was opaque dark brown and high viscus liquid. It also had a irritant order which was different from PCBlike order. The brown substance which was not dissolved with $n$-hexane was present in it. $\mathrm{H}-2$ was used for $c a .3$ years at 200 to $220^{\circ} \mathrm{C}$ at a factory where the rice oil was produced. It was transparent pale brown liquid and had PCBlike order. H-3 was opaque dark brown and high viscus liquid and had PCB-like order. The temperature and period used were not clear.

\section{2 Reagents}

Florisil of 60 to 80 mesh was activated overnight at $130^{\circ} \mathrm{C}$. Silica gel TLC plate was Wakogel FM Plate $(20 \times 20 \mathrm{~cm})$ of Wako Pure Chemical Co. Ltd. Methylene dichloride, ethanol, diethyl ether, $n$-hexane and anhydrous sodium sulfate were reagent for PCB analysis of Wako Pure Chemical Co. Ltd.

\section{3 Methods}

\section{1) Preparation of $P C Q$ standard}

As shown in Scheme 1, PCQ in $\mathrm{H}-3$ was purified by repeating of Florisil column and silica gel thin layer chromatography, checking by gel permeation chromatography (GPC). One

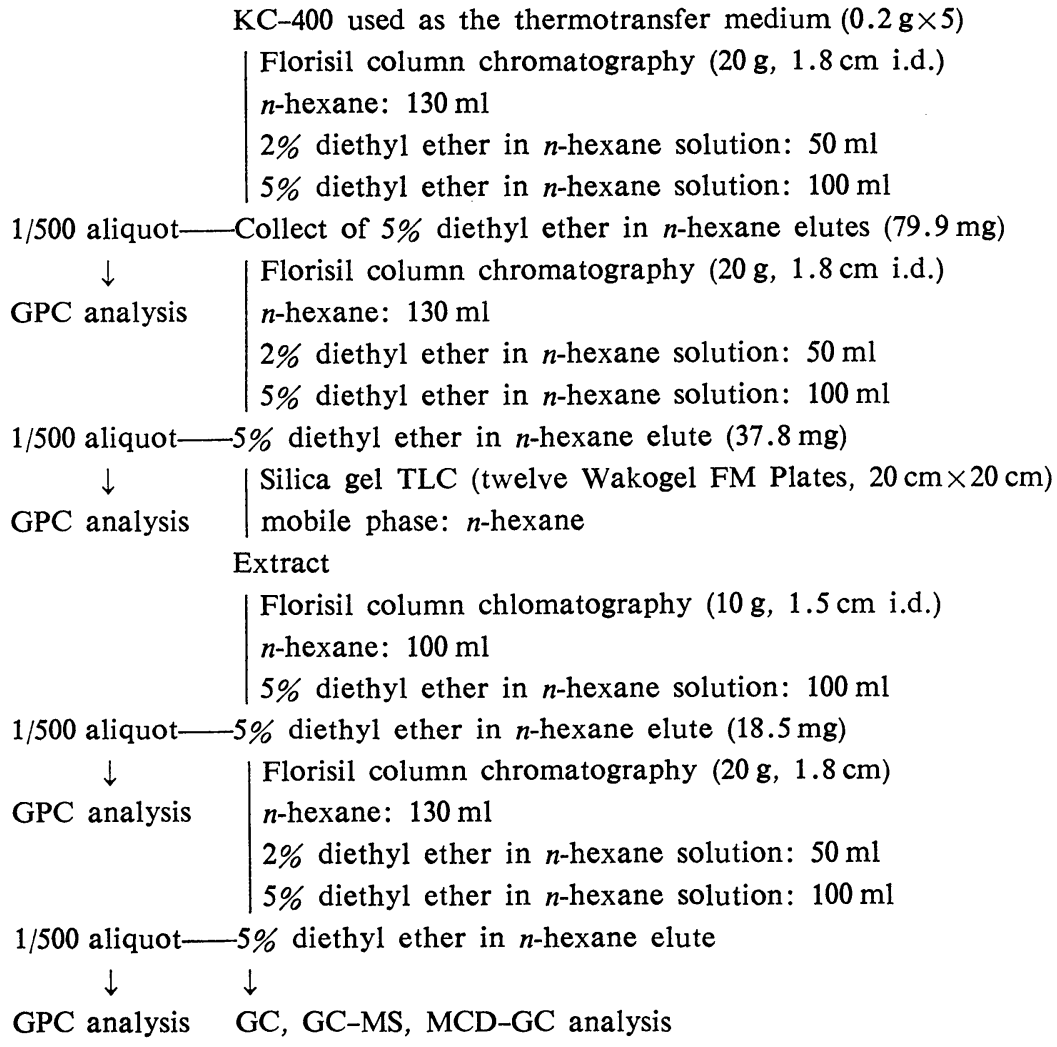

Scheme 1. Procedure for the purification of PCQ in KC-400 used as the thermotransfer medium (H-3) 
gram of H-3 was dissolved with $25 \mathrm{ml}$ of $n$ hexane, and each of $1 / 5$ aliquot was put on a Florisil column $(20 \mathrm{~g}, 1.8 \mathrm{~cm}$ i.d. $)$ and eluted with: successive $130 \mathrm{ml}$ of $n$-hexane, $50 \mathrm{ml}$ of $2 \%$ diethyl ether in $n$-hexane and $100 \mathrm{ml}$ of $5 \%$ diethyl ether in $n$-hexane solution. The five third fractions were collected, concentrated and rechromatographed over a Florisil column $(20 \mathrm{~g}$, $1.8 \mathrm{~cm}$ i.d.). The third fraction was concentrated and purified further by silica gel TLC. Sample was spotted on twelve silica gel plates and developed with $n$-hexane. The portion of UV band corresponding to PCQ in each plate was scraped off, extracted with benzene, concentrated and dried. The residure was dissolved with $3 \mathrm{ml}$ of $n$-hexane and chromatographed with successive $100 \mathrm{ml}$ of $n$-hexane and $100 \mathrm{ml}$ of $5 \%$ diethyl ether in $n$-hexane solution on a Florisil column $(10 \mathrm{~g}, 1.5 \mathrm{~cm}$ i.d.). The five percentage diethyl ether in $n$-hexane fraction was concentrated, placed on a Florisil column $(20 \mathrm{~g}, 1.8 \mathrm{~cm}$ i.d.) and rechromatographed with successive $130 \mathrm{ml}$ of $n$-hexane, $50 \mathrm{ml}$ on $2 \%$ diethyl ether in $n$-hexane and $100 \mathrm{ml}$ of $5 \%$ diethyl ether in $n$-hexane solution. The third fraction (purified PCQ fraction) was concentrated, dried, kept in a constant temperature box at $85^{\circ} \mathrm{C}$, and weighed once an hour until the weight reached a constant value. The impurities in the purified PCQ fraction were examined by FID-GC, ECD-GC and GC-MS.

GC-MS analysis was carried out on a Shimadzu LKB-9000 B equipped with the computer system. GC-MS condition showed following: Column, $1 \mathrm{~m} \times 3 \mathrm{~mm}$ glass column packed with $2 \% \mathrm{OV}-$ 210 on Gaschrom $\mathrm{Q}(100 / 120$ mesh); Column, Injector, Ionsorce and Separator temp., 220, 250, 280 and $290^{\circ} \mathrm{C}$, respectively; Electron energy, $20 \mathrm{eV}$; Accel. volt., $3.5 \mathrm{kV}$; Carrier gas, He (30 $\mathrm{ml} / \mathrm{min})$; Scanning, once every ten seconds; Scanning range, 300 to $700 \mathrm{~m} / e$. Moreover, the chlorine in the fraction was determined by MCDGC. MCD-GC condition showed following: Column, $70 \mathrm{~cm} \times 2 \mathrm{~mm}$ glass column packed with $2 \%$ SE-30 on Gaschrom Q (100/120 mesh); Injection temp., $240^{\circ} \mathrm{C}$; Detector temp., $250^{\circ} \mathrm{C}$; Column temp., programmed from 225 to $250^{\circ} \mathrm{C}$ $\left(20^{\circ} \mathrm{C} / \mathrm{min}\right)$; Carrier gas, $\mathrm{N}_{2}(35 \mathrm{ml} / \mathrm{min})$; Transfer, Reaction and Outlet temp., 650,840 and $840^{\circ} \mathrm{C}$, respectively; Range, $50 \mathrm{ohm}$; Reactant gas, $\mathrm{O}_{2}$ $(100 \mathrm{ml} / \mathrm{min})$; Bias volt., $250 \mathrm{mV}$; Gain, high 360 .
2) Purification and determination of $P C Q$ in Kanemi rice oil

Sample was saponified, extracted and concentrated according to the method described previously. ${ }^{2)}$ Ten concentrated extract was put on a Florisil column $(20 \mathrm{~g}, 1.8 \mathrm{~cm}$ i.d. $)$ and eluted successively. with $130 \mathrm{ml}$ of $n$-hexane, 50 $\mathrm{ml}$ of $2 \%$ diethyl ether in $n$-hexane and $100 \mathrm{ml}$ of $5 \%$ diethyl ether in $n$-hexane solution. The third fraction was analysed By MCD-GC (for the determination of the chlorine content of PCQ) and ECD-GC (for the determination of PCQ). The determination of PCQ was carried out by comparing the total areas in the gas chromatogram of the PCQ fraction with that of PCQ standard.

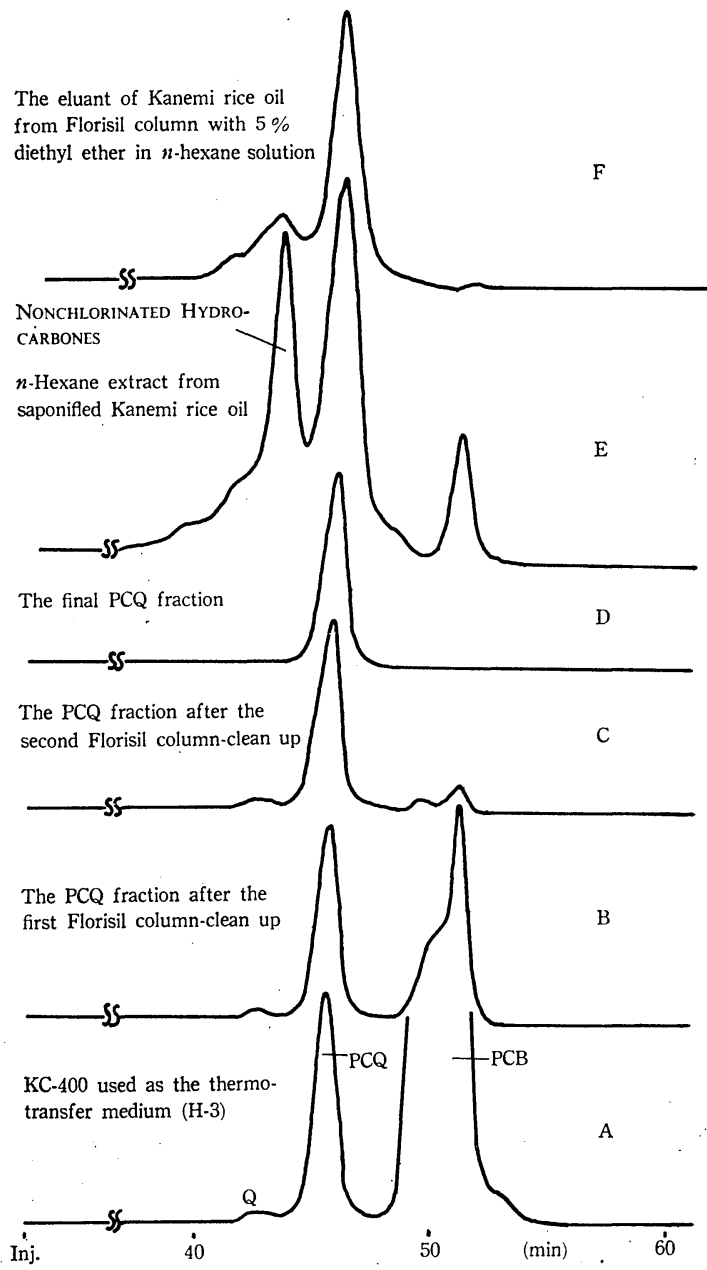

Fig. 1. Gel permeation chromatograms of Kanemi rice oil eluant from Florisil column with 5\% diethyl ether in $n$-hexane solution and the PCQ fraction separated from $\mathrm{KC}-400$ used as the thermotransfer medium: $(\mathrm{H}-3)$ 
The ECD-GC condition was described previously. ${ }^{2)}$

3) Purification and determination of $P C Q$ in $K C-400$ s used as the thermotransfer media and in heated $\mathrm{KC}-400$

A tenth gram of sample was dissolved with $3 \mathrm{ml}$ of $n$-hexane and chromatographed over a Florisil column $(20 \mathrm{~g}, 1.8 \mathrm{~cm}$ i.d. $)$ using to the same method described in (Method-2). The five percentage diethyl ether in $n$-hexane fraction was concentrated, spotted on a silica gel plate and developed with $n$-hexane. The portion of UV band corresponding to PCQ was scraped off, extracted with benzene and concentrated. The extract was analysed for the determination of PCQ.

4) Heat treatment of $\mathrm{KC}-400$

$\mathrm{KC}-400$ which had been heated before ${ }^{4)}$ was used in this study. $\mathrm{KC}-400(2.6 \mathrm{ml})$ was poured into $8 \mathrm{~cm} \times 1.5 \mathrm{~cm}$ i.d. a pyrex glass ampoule. After sealing, it was heated in the electric furnace under various conditions indicated in Table 3.

\section{Results and Discussion}

\section{1 PCQ standard}

Fig. 1-A showed the GPC chromatogram of $\mathrm{KC}-400$ used as the thermotransfer medium $(\mathrm{H}-3)$. Peak $\mathrm{Q}$, first eluted from the column, might be organochlorinated compounds with higher molecular weight than that of PCQ.

As shown in Fig. 1B, the most of PCB was removed by the first Florisil column-clean up, but the PCQ fraction (5\% diethyl ether in $n$ hexane eluant) was fairly contaminated with PCB.

Therefore, the fraction was rechromatographed over a Florisil column, but polar PCB remained in the PCQ fraction (Fig. 1-C).

Then, the PCQ fraction was purified by silica gel thin layer chromatography.

Figure 2 showed the TLC chromatogram of standards and the PCQ fraction. The lowest UV spot (spot Q) corresponded to the peak $Q$ shown in Fig. 1-A. The portion of UV band corresponding to PCQ was scraped off and extracted with benzene. However, the extract was still contaminated with the large amount of hydrocarbons from the adsorbent of the thin layer.

Therefore, the fraction was purified by two more Florisil column chromatophies. As shown

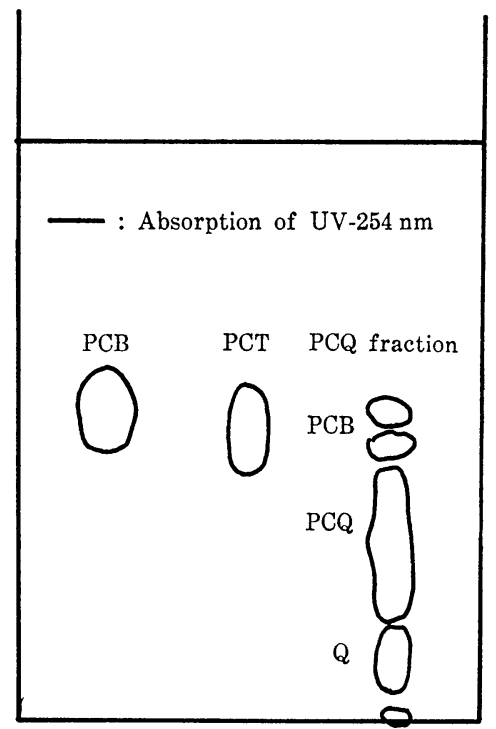

Fig. 2. Thin layer chromatogram of $\mathrm{PCB}(\mathrm{KC}-400)$, PCT (Aroclor 5460) and the PCQ fraction of H-3 after the second Florisil column-clean up TLC plate, Wakogel FM Plate; mobile phase, $n$-hexane

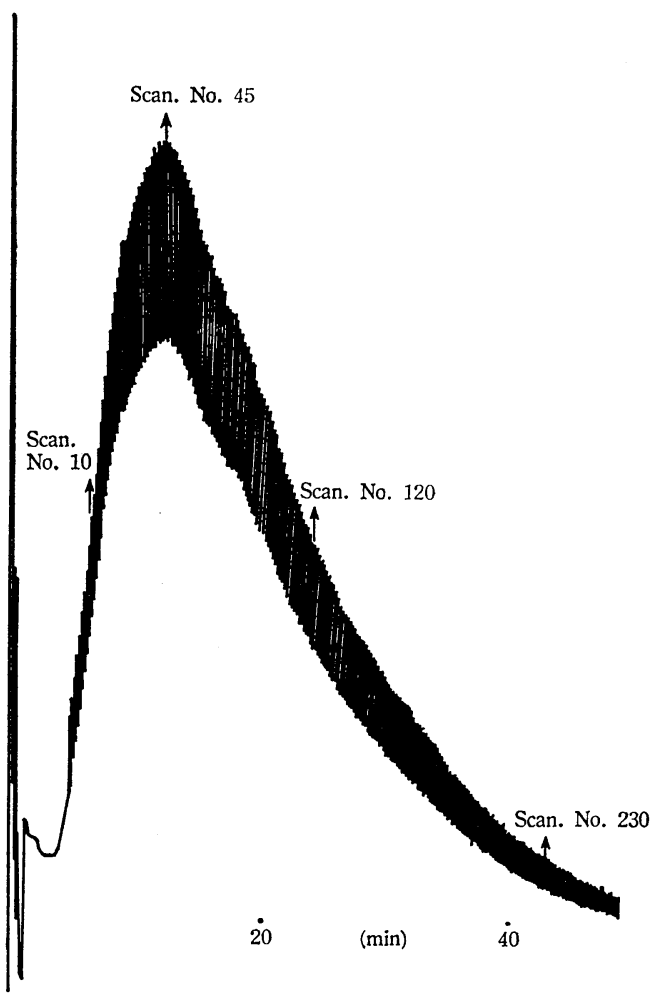

Fig. 3. Total ion current chromatogram (by GCMS with the computer system) of the final PCQ fraction 
in Fig. 1-D, PCB and the compounds with the higher molecular weight were not shown in the final PCQ fraction, and the weight of the fraction was $18 \mathrm{mg}$.

However, FID-GC and ECD-GC analysis revealed that the fraction contained $2 \%$ as the impurity.

Figure 3 showed the total ion current chromatogram of the final PCQ fraction.

Figure 4-A, B, C, and D showed the mass
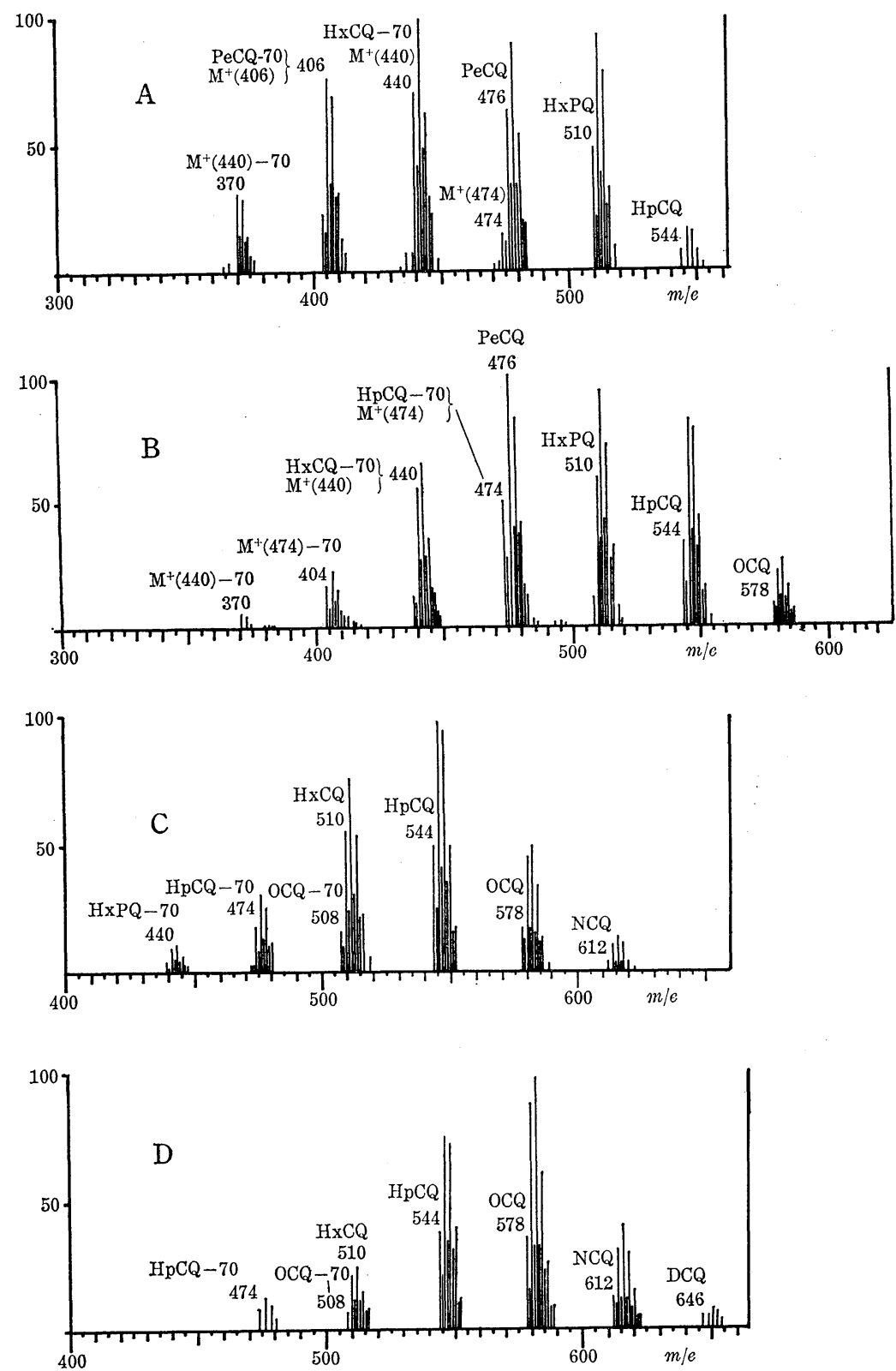

Fig. 4. Mass spectra of scanning No. 10, 45, 120 and 230 as shown in Fig. 3 A, B, C and D showed mass spectrum of scanning No. 10, 45, 120 and 230, respectively.

PeCQ, HxCQ, HpCQ, OCQ, NCQ and DCQ showed penta-, hexa-, hepta-, octa-, nona- and deca-chloeinated quaterphenyl, respectively. 


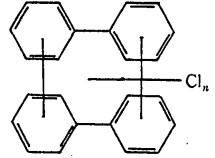

Fig. 5. Possible stracture for $\mathrm{M}^{+}(406), \mathrm{M}^{+}(440)$ and $\mathrm{M}^{+}(474)$ in Fig. $4 \mathrm{~A}$ and $\mathrm{B} n=3 \sim 5$

spectra of scanning No. 10, 45, 120, and 230, respectively, in Fig. 3. The fragments of PCQ as well as PCB and PCT showed the strong peak at the molecular ion $\left(\mathrm{M}^{+}\right)$and minor peaks at $\left(\mathrm{M}^{+}-70\right)$, a fragment eliminated of double chlorine atoms from $\left(\mathrm{M}^{+}\right)$. Figure 4A showed that penta- to hepta-chlorinated quaterphenyl were persent in the scanning No. 10.

It was supposed that $\mathrm{M}^{+}(406), \mathrm{M}^{+}(440)$ and $\mathrm{M}^{+}(474)$ in Fig. 4-A and $\mathrm{B}$ might be cyclic structures of the type depicted in Fig. 5.

Figure 4 also showed that the ratio of the higher chlorinated PCQ increased with increasing of scanning number.

GC-MS analysis became clear that the final PCQ fraction contained bits of unknown compounds but that the fraction mainly composed of penta- to deca-chlorinated quaterphenyls.

Moreover, MCD-GC revealed that the chlorine content of the PCQ fraction was $45.5 \%$.

The PCQ fraction was used as PCQ standard for the determination of PCQ in samples by ECD-GC.

\section{2 The PCQ level in Kanemi rice oil caused the "Yusho"}

As shown in Fig. 1-E, $n$-hexane extract from saponified Kanemi rice oil which was manufactured on February 10th in 1968 contained large quantities of non-chlorinated hydrocarbones and PCB. The hydrocarbones and the most amount of PCB were eliminated from the extract by Florisil column-clean up.

As shown in Fig. 1-F, the PCQ fraction contained unknown materials which were appeared to be chlorinated compounds with the higher molecular weight than PCQ, but the unknown didn't disturb the PCQ determination by ECDGC and MCD-GC analysis because they eluted later than PCQ from GC-column (2\% OV-210 on Gaschrom Q).

As shown in Table 1, the chlorine concentration of PCQ in the oil was 207 to $450 \mathrm{ppm}$.

The values were equivalent to $72 \sim 89 \%$ of organochlorine compounds, which were free from $\mathrm{PCB}$ and PCDF, in the oil reported previously. ${ }^{1), 2)}$

It was supposed that $11 \sim 28 \%$ of organochlorine compounds might attribute to unknown materials.

The actual PCQ level in the oil also was determined by ECD-GC. As shown in Table 1, the PCQ level in the oil was 490 to $866 \mathrm{ppm}$, equivalent to $0.88 \sim 3.46$ times more than the actual PCB level in the oil.

It had been considered that all the chlorine in Kanemi rice oil was derived from PCB, and consequently the PCB concentration was calculated from the total chloride level in the oil in 1969 to $\left.1970 .{ }^{8)}, 8\right)$

However, this study revealed that the estimated PCB concentration was the level which contained

Table 1. The Chlorine Concentration of PCQ, PCB and PCDF in Kanemi Rice Oils Caused the "Yusho"

\begin{tabular}{|c|c|c|c|c|c|c|c|c|}
\hline \multirow[b]{2}{*}{ Production date } & \multicolumn{4}{|c|}{ Concentration of chlorine (ppm) } & \multirow{2}{*}{$\mathrm{PCB}^{(\mathbf{c}), 6)}$} & \multirow{2}{*}{$\mathrm{PCDF}^{5), 6)}$} & \multirow{2}{*}{$\begin{array}{c}\mathrm{PCQ} / \mathrm{PCB} \\
(\mathrm{g} / \mathrm{g})\end{array}$} & \multirow{2}{*}{$\begin{array}{c}\mathrm{PCDF} / \\
\mathrm{PCB} \\
(\mathrm{g} / \mathrm{g})\end{array}$} \\
\hline & $\begin{array}{c}\text { Original } \\
\text { sample }\end{array}$ & $\begin{array}{l}\text { Hexane } \\
\text { extract }\end{array}$ & $\left.O C^{b}(1), 2\right)$ & PCQ & & & & \\
\hline Feb. 5th, 1968 & 1,485 & 997 & 537 & $450(866)$ & $500(983)$ & $3.98(7.40)$ & 0.88 & 0.008 \\
\hline Feb. 9th, 1968 & 554 & 443 & 287 & $207(490)$ & $80(151)$ & $0.95(1.90)$ & 3.25 & 0.013 \\
\hline Feb. 10th, 1968 & 446 & 462 & 343 & $248(536)$ & $83(155)$ & $1.15(2.25)$ & 3.46 & 0.015 \\
\hline Feb. 21st, 1968 & 11 & 13 & & & & & & \\
\hline
\end{tabular}

a) Hexane extract from the saponified sample

b) Organochlorinated compounds in the hexane extracts from saponified oils that were not PCB nor PCDF

c) The values were calculated from the concentration of PCB with the method of the author et al. . $^{7}$ The figures in parenthesis show the concentration of each compound. 
Table 2. The Concentration of PCQ and PCDF in KC-400s Used as the Thermotransfer Media

\begin{tabular}{c|c|c|c|c} 
Sample & $\begin{array}{c}\text { Used temp. } \\
\left({ }^{\circ} \mathrm{C}\right)\end{array}$ & $\begin{array}{c}\text { Used period } \\
\text { (year) }\end{array}$ & $\begin{array}{c}\text { Concentration of } \\
\text { PCQ }(\mathrm{ppm})\end{array}$ & $\begin{array}{c}\text { Concentration of } \\
\text { PCDF (ppm) }\end{array}$ \\
\hline $\mathrm{H}-1$ & $180 \sim 270$ & 14 & 31,000 & 510 \\
$\mathrm{H}-2$ & $200 \sim 220$ & $c a .3$ & 690 & 277 \\
$\mathrm{H}-3$ & not clear & not clear & 28,000 & 20
\end{tabular}

PCB, PCQ, PCDF and bits of unknown organochlorinated compounds. It also became clear that the actual PCB level in the oil was barely as $1 / 3$ to $1 / 7$ times as the estimated PCB level and that the PCQ concentration in the oil was 0.88 to 3.46 times more than the actual PCB level.

\section{3 The PCQ formation}

It was considered that all organochlorinated compounds in Kanemi rice oil were derived from $\mathrm{KC}-400$ used as the thermotransfer medium, which had leaked out into Kanemi rice oil in the deodorized tank.

Therefore, KC-400s which had been used as the thermotransfer media were analysed for PCQ.

As shown in Table 2, PCQ was detected in all thermotransfer media, and the PCQ level in them wàs 690 to $31,000 \mathrm{ppm}$.

It was supposed that PCQ might generate from $\mathrm{KC}-400$ during the period when $\mathrm{KC}-400$ was used as the thermotransfer media because PCQ wasn't detected in the commercial KC-400 preparation.

In regard to the PCQ formation, there was only a report which PCQ generated photochemically from original PCB by irradiating PCB with UV lamps or sunlight. ${ }^{3)}$ Therefore, it was investigated whether PCQ would generate thermo-

Table 3. The Concentration of PCQ and PCDF in Heated KC-400

\begin{tabular}{|c|c|c|c|c|}
\hline Heating temp. $\left({ }^{\circ} \mathrm{C}\right)$ & $\begin{array}{c}\text { Heating period } \\
\text { (day) }\end{array}$ & Additive & $\begin{array}{l}\text { Concentration } \\
\text { of PCQ (ppm) }\end{array}$ & $\begin{array}{c}\text { Concentration } \\
\text { of PCDF }(\mathrm{ppm})^{4}\end{array}$ \\
\hline Room temp. & 0 & & 0 & 33 \\
\hline 180 & 5 & & 450 & 41 \\
\hline 250 & 5 & & 710 & 40 \\
\hline 300 & 5 & & 2,000 & \\
\hline$" \prime$ & 6 & & 5,700 & 35 \\
\hline$"$ & 10 & & 4,000 & 34 \\
\hline " & 15 & & 3,300 & 41 \\
\hline$" \prime$ & 30 & & 11,000 & \\
\hline 360 & 2 & & 7,400 & 84 \\
\hline$" \prime$ & 10 & & 7,300 & 94 \\
\hline$"$ & 20 & & 14,000 & 65 \\
\hline 300 & 3 & $\mathrm{~S}^{\mathrm{a})}$ & 3,500 & 55 \\
\hline$" \prime$ & 5 & $\mathrm{~S}$ & 1,800 & 46 \\
\hline 360 & 2 & $\mathrm{~S}$ & 13,000 & 188 \\
\hline$" \prime$ & 5 & $S$ & 14,000 & 182 \\
\hline$"$ & 10 & $\mathrm{~S}$ & 25,000 & 205 \\
\hline " & 20 & $\mathrm{~S}$ & 23,000 & 77 \\
\hline$"$ & 2 & $W^{b)}$ & 20,000 & 223 \\
\hline$" \prime$ & 20 & w & 37,000 & 212 \\
\hline " & 2 & $\mathrm{~S}+\mathrm{W}$ & 3,800 & 101 \\
\hline$"$ & 20 & $\mathrm{~S}+\mathrm{W}$ & 47,000 & 71 \\
\hline
\end{tabular}

a) Stainless steel

b) Water 


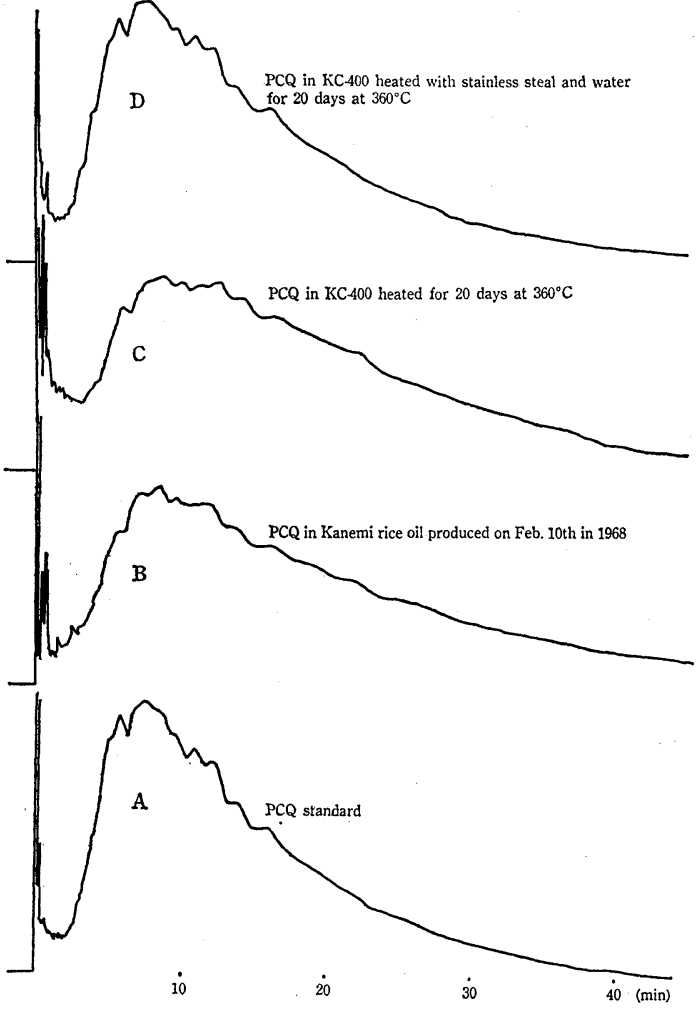

Fig. 6. Gas chromatograms of $\mathrm{PCQ}$ in $\mathrm{KC}-400$ used as the thermotransfer medium $(\mathrm{H}-3)$, Kanemi rice oil and heated $\mathrm{KC}-400$ s

chemically from $\mathrm{PCB}$ by heating $\mathrm{KC}-400$ in a glass ampoule.

As shown in Table 3, it was confirmed that PCQ generated from original KC- 400 when KC400 was heated at high temperature in a glass ampoule. It also became clear that the PCQ level in KC-400 increased by heating at higher temperature and during longer period.

Moreover, the PCQ level increased when KC400 was heated under the addition of stainless steel. It was supposed that stainless steel might act catalytically on the PCQ formation.

The PCQ level also increased by heating under the addition of water. Perhaps, water increased the pressure in a ampoule, and consequently the PCQ formation might be accelerated.

Therefore, when KC-400 was heated for 20 days at $360^{\circ} \mathrm{C}$ under the addition of stainless steel and water, the PCQ concentration became the maximum level, 47,000 ppm.

In addition, as shown in Fig. 6, the gas chromatogram of PCQ in heated $\mathrm{KC}-400$ was more or less different according to the heating condition, especially the additive, i.e., the PCQ composition varried according to the heating condition.

When $\mathrm{KC}-400$ was heated under additives, the ratio of less chlorinated quaterphenyl increased in comparison with PCQ in $\mathrm{KC}-400$ heated only (Fig. 6).

The gas chromatogram of PCQ in Kanemi rice oil was similar to that of PCQ in $\mathrm{KC}-400$ heated only, and also the gas chromatogram of the PCQ standard resembled that of PCQ in KC-400 heated under the addition of stainless steel and water (Fig. 6).

On the other hand, it wasn't correlative between the PCQ and PCDF concentration in the thermotransfer media and in heated $\mathrm{KC}-400$ as shown in Table 2 and 3 . This result suggested that the mechanism for the PCQ formation was different from that of the PCDF formation.

From the results described above, it became clear that PCQ generated from original KC-400 during the period when $\mathrm{KC}-400$ was used as the thermotransfer media.

However, the ratios of $\mathrm{PCQ} / \mathrm{PCB}$ and $\mathrm{PCDF} /$ $\mathrm{PCB}$ in the thermotransfer media were fairly lower than those of Kanemi rice oil. The difference might be explained as follows: After KC-400 which was used as the thermotransfer medium leaked out into Kanemi rice oil in the deodorization tank, the ratios of $\mathrm{PCQ} / \mathrm{PCB}$ and PCDF/PCB in the oil might become extraordinarily high by deodorizing.

The authors are currently working to identify additional unknown organochlorinated compounds in Kanemi rice oil and the thermotransfer media, and also to resolve the high ratios of $\mathrm{PCQ} / \mathrm{PCB}$ and $\mathrm{PCDF} / \mathrm{PCB}$ in the oil.

\section{References}

1) Miyata, H., Kashimoto, T., Kunita, N.: J. Food Hyg. Soc. Japan, 19, 126 (1978).

2) Miyata, H., Kashimoto, T., Kunita, N.: ibid., 19, 364 (1978).

3) Hutzinger, O., Jamieson, W. D., Safe, S., MacNeil, D., Zikto, V.: "The Chemistry of PCBs," p. 121 (1974), CRC Press, Ohio.

4) Miyata, H., Kashimoto, T.: J. Food Hyg. Soc. Japan, 19, 78 (1978). 
5) Miyata, H., Kashimoto, T., Kunita, N.: ibid., 18, 260 (1977).

6) Miyata, H., Watanabe, I., Kashimoto, T., Kunita, N.: Osaka Prefectural Institute of Public Health, ED. of Food Sanitation, 8, 87 (1977).

7) Ugawa, M., Nakamura, A., Kashimoto, T.:
J. Food Hyg. Soc. Japan, 14, 415 (1973).

8) Tukamoto, H. et al.: Fukuoka Acta Med., 60, 496 (1969).

9) Special report on the prevention, diagnosis and treatment for the "Yusho," Science and Technology Agency, p. 19 (1970). 